\title{
Article
}

\section{Screening for Parasitic Infection and Tuberculosis in Immunosuppressed and Pre-Immunosuppressed Patients: An Observational Study}

\author{
Luisa Carnino $^{1,2, *}$, Jean-Marc Schwob ${ }^{1} \mathbb{D}$, Dionysios Neofytos ${ }^{3} \mathbb{D}$, Maria Lazo-Porras ${ }^{1,4}$, François Chappuis ${ }^{1,2}$ \\ and Gilles Eperon 1,2
}

Citation: Carnino, L.; Schwob, J.-M.; Neofytos, D.; Lazo-Porras, M.; Chappuis, F.; Eperon, G. Screening for Parasitic Infection and Tuberculosis in Immunosuppressed and

Pre-Immunosuppressed Patients: An Observational Study. Trop. Med. Infect Dis. 2021, 6, 170. https://doi.org/ 10.3390 /tropicalmed6030170

Academic Editors: Amyn A. Malik, Tapash Roy, Abu Naser Zafar Ullah and Sourya Shrestha

Received: 18 August 2021

Accepted: 17 September 2021

Published: 21 September 2021

Publisher's Note: MDPI stays neutral with regard to jurisdictional claims in published maps and institutional affiliations.

Copyright: (c) 2021 by the authors Licensee MDPI, Basel, Switzerland. This article is an open access article distributed under the terms and conditions of the Creative Commons Attribution (CC BY) license (https:// creativecommons.org/licenses/by/ $4.0 /)$.
1 Division of Tropical and Humanitarian Medicine, Geneva University Hospitals, Rue Gabrielle-Perret-Gentil 6, 1205 Geneva, Switzerland; jean-marc.schwob@hcuge.ch (J.-M.S.); maria.lazo.porras@gmail.com (M.L.-P.); francois.chappuis@hcuge.ch (F.C.); gilles.eperon@hcuge.ch (G.E.)

2 Faculty of Medicine, University of Geneva, Rue Michel-Servet 1, 1205 Geneva, Switzerland

3 Division of Infectious Diseases, Geneva University Hospitals, Rue Gabrielle-Perret-Gentil 6, 1205 Geneva, Switzerland; dionysios.neofytos@hcuge.ch

4 CRONICAS Center of Excellence in Chronic Diseases, Universidad Peruana Cayetano Heredia, Lima 15102, Peru

* Correspondence: Luisa.carnino@hcuge.ch; Tel.: +41-(0)223729611; Fax: +41-(0)223729626

Abstract: Reactivation of latent tuberculosis infection (LTBI) or latent parasitic infection (LPI) during drug-induced immunosuppression can have serious consequences. The Division of tropical and humanitarian medicine of the Geneva University Hospitals runs a specific consultation for parasitic screening of immunosuppressed or pre-immunosuppressed patients. We sought to determine the seroprevalence of LTBI and LPI in such patients and explore its relationship with country of origin or previous travel in a retrospective, single-centre observational study from 2016 to 2019. Demographic data, travel history, ongoing treatments and results of the parasitological (Strongyloides stercoralis, Trypanosoma cruzi, Echinococcus multilocularis, Entamoeba histolytica and Leishmania spp.) and TB screening were collected to calculate LPI or LTBI prevalence. Risk factors for LTBI and strongyloidiasis were analysed using Poisson regression with robust variance. Among 406 eligible patients, 24/353 (6.8\%) had LTBI, 8/368 (2.2\%) were positive for Strongyloides stercoralis infection, 1/32 (3.1\%) was positive for Entamoeba histolytica and 1/299 (0.3\%) was positive for Leishmaniasis. No cases of Trypanosoma cruzi $(0 / 274)$ or Echinococcus multilocularis (0/56) infection were detected. Previous travel to or originating from high-prevalence countries was a risk factor for LTBI (PR = 3.4, CI 95\%: 1.4-8.2 and 4.0, CI 95\%: 1.8-8.9, respectively). The prevalence of serological Strongyloidiasis in immunosuppressed patients is lower in comparison to those without immunosuppression ( $\mathrm{PR}=0.1, \mathrm{CI} 95 \%$ : 0.01-0.8). In conclusion, screening before immunosuppression needs to be individualized, and LTBI and LPI need to be ruled out in patients who originate from or have travelled to high-prevalence countries. The sensitivity of strongyloidiasis serology is reduced following immunosuppression, so an algorithm combining different tests or presumptive treatment should be considered.

Keywords: parasitological screening; latent tuberculosis infection; immunosuppression; Strongyloides stercoralis; Trypanosoma cruzi; Echinococcus multilocularis; Entamoeba histolytica; Leishmania spp.

\section{Introduction}

The reactivation of latent tuberculosis infection (LTBI) or parasitic infection (LPI) during drug-induced immunosuppression can have serious consequences on patients' health. The number of patients receiving immunosuppressive therapy has been increasing following the ongoing introduction of new immunosuppressive and immunomodulatory (ISIM) agents for treatment of autoimmune diseases, and solid and hematologic malignancies. It is estimated that between $2.8 \%$ and $6 \%$ of the American population takes such treatments $[1,2]$. A higher degree of immunosuppression means higher risk of the acquisition 
or reactivation of imported parasitic diseases [3]. Currently, there are no clear guidelines on which type of (and if) LPI screening should be performed before starting most ISIM regimens.

The Geneva canton is a multicultural, high-income area in Switzerland with more than 500,000 inhabitants, in which about 2/3 of its documented population has a foreign citizenship and half was born abroad $[4,5]$. Over $30 \%$ of the population comes from the Mediterranean basin, and approximately $10 \%$ are equally distributed between sub-Saharan Africa, Latin America and Asia [4]. In addition, it is estimated that over 10,000 undocumented immigrants, mostly from Latin America and Africa, live in the canton [6]. As such, the situation bears similarities to many other urban centres of high-income countries. Since most ISIM drugs are used in the European and North American markets, little attention has been paid to recommendations regarding screening for tropical/imported parasites. However, in Geneva and elsewhere, an increasing proportion of patients on ISIM had previous exposure to such pathogens. At the Division of Tropical and Humanitarian Medicine (Service de Médecine Tropicale et Humanitaire, SMTH) of the Geneva University Hospitals (Hôpitaux Universitaires de Genève, HUG), immunosuppressed or pre-immunosuppressed patients are screened for tuberculosis and a number of parasites (Strongyloides stercoralis, Trypanosoma cruzi, Echinococcus multilocularis, Entamoeba histolytica, Leishmania spp.), based on expert opinion [7-11]. The aim of this study was to retrospectively assess the prevalence and risk factors for LTBI and LPI of patients treated with ISIM agents.

\section{Methods}

\subsection{Study Design, Setting and Participants}

This was a retrospective, single-centre, cross-sectional, observational study. The eligible population included patients 18 years old and over who had attended the consultation for immunosuppressed patients at SMTH between December 2016 and December 2019. The main objective of this consultation was to update immunization before or during treatment with one or more ISIM drugs. Furthermore, since 2016, screening for LTBI, viral cosmopolitan infections (HIV, HBV, HCV, CMV, EBV, HSV, data not shown) and LPI screening has been offered (Figure 1). Included in this study were: patients affected by all types of chronic conditions for which ISIM treatment may be prescribed, already treated with ISIM drugs or for whom an impending treatment with one of those drugs, as listed in Supplementary Material Table S1, was planned. Most of the patients had been diagnosed with an immune-mediated inflammatory disease and were referred by different specialists in neurology, dermatology, rheumatology and oncology. The study was approved by the local Ethics Committee (Canton of Geneva, approval No. 2020-01647). Patients whose medical charts documented their refusal to participate in a clinical research study were excluded.

\subsection{Screening Test Indications}

Patients were screened following the algorithm shown in Figure 1. The QuantiFERON-TB Gold ${ }^{\circledR}$ (QFT, Germantown, MD, USA) test for the diagnosis of latent tuberculosis was recommended according to the type of immunosuppressive treatment. Serological screening for Strongyloides stercoralis, Trypanosoma cruzi, Entamoeba histolytica, Leishmania spp. was performed depending on previous exposure in endemic regions (travel or having lived more than 4 weeks in a high-risk country), while screening for Echinococcus multilocularis was proposed since July 2019, in case of a specific exposure (e.g., living in a farmhouse, consumption of grown leaf or root vegetable, ingestion of food potentially contaminated by fox feces, owning dogs or cat that roamed outdoors unattended) [12]. Finally, a PCR stool test for amoebiasis was performed according to travel exposition and in patients affected by an inflammatory bowel disease (IBD). 


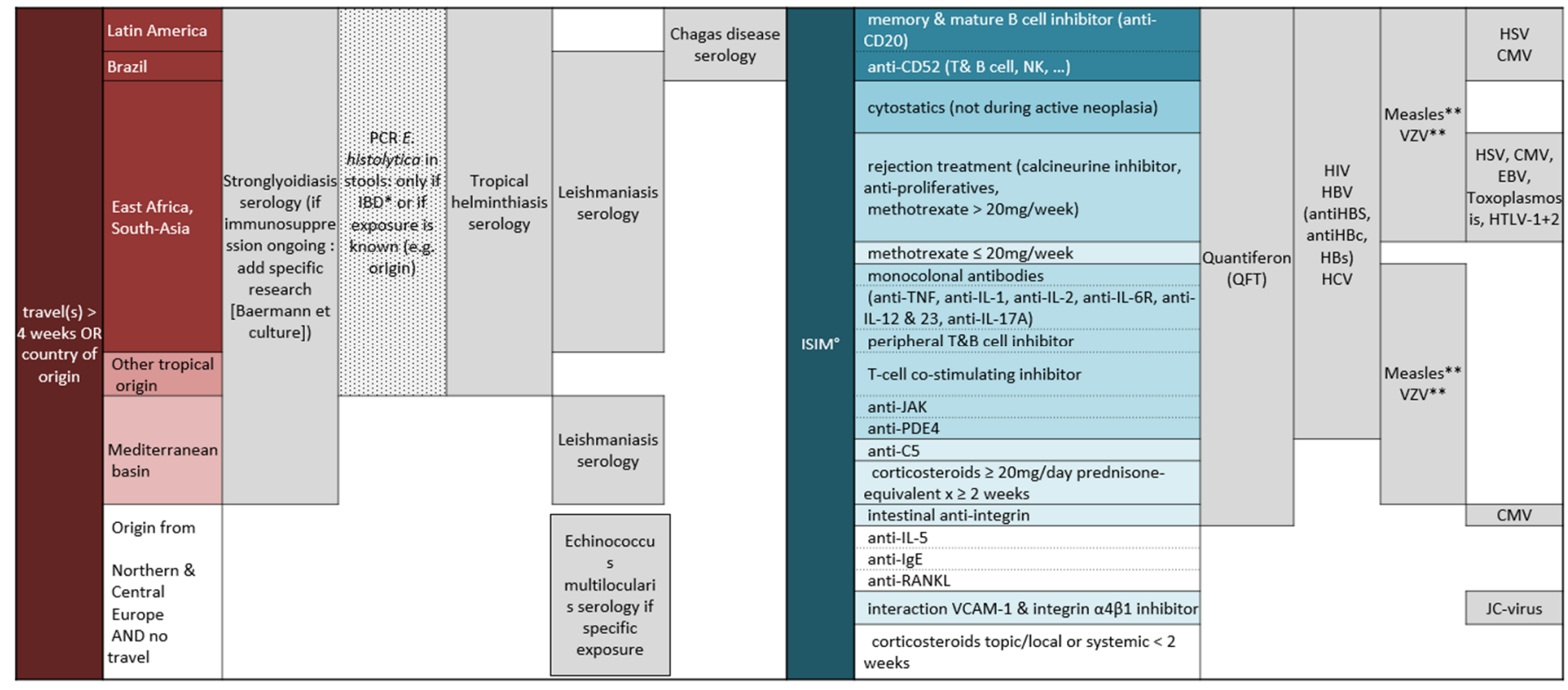

Figure 1. Screening algorithm according to travel exposition and type of immunosuppression ${ }^{\times} ;{ }^{\times}$The algorithm was adapted from Eperon et al., RMS 2018, 14: 922-933; * IBD: inflammatory bowel disease; ${ }^{\circ}$ ISIM: immunosuppressive and immunomodulatory agents; ${ }^{* *}$ If negative, vaccinate before immunosuppression. QFT: Quantiferon; HIV: Human immunodeficiency virus; HBV: Hepatitis B virus; HCV: Hepatitis C virus; VZV: Varicella-zoster virus; HSV: Herpes simplex virus; CMV: Cytomegalovirus; EBV: Epstein-Barr virus; HTLV-1: human T-cell lymphotropic virus type 1; JC-virus: John Cunningham virus.

\subsection{Laboratory Tests}

Type of screening test and cut-off values are shown in Table 1. Depending on availability, the tests were performed at HUG, at the Swiss Tropical and Public Health Institute of Basel (Swiss TPH) or at the Institute for Infectious Disease of the University Hospital of Bern. For strongyloidiasis, the serological screening method changed during the time frame of the study: from 2016 to September 2018 an in-house ELISA IgG (S. ratti antigen) was used at the Swiss TPH with a cut-off for a positive result at $\geq 0.7$ optical density (OD). From October 2018 onwards, a confirmation test (ELISA IgG Euroimmune ${ }^{\circledR}$, Lübeck, Germany; $S$. papillosus antigen) was added if the in-house screening test result was $\geq 0.5 \mathrm{OD}$. The serological result was considered as positive according to the definition used at the time the test was performed.

Table 1. Screening test type and cut off.

\begin{tabular}{ccc}
\hline Pathogen & Test & Cut Off Value \\
\hline Mycobacterium tuberculosis & & $\begin{array}{c}\text { Positive } \geq 0.35 \mathrm{IU} / \mathrm{mL} \\
\text { Indeterminate: blood cells have not } \\
\text { responded to a positive control stimulant. } \\
\text { Negative }<0.35 \mathrm{IU} / \mathrm{ml} \\
\text { Positive }>0.7 \mathrm{OD}\end{array}$ \\
Strongyloides spp. & Quantiferon ${ }^{\circledR}$ & $\begin{array}{c}\text { Doubtful } \geq 0.5 \leq 0.69 \text { OD } \\
\text { Negative }<0.5 \text { OD } \\
\text { Negative }<0.8\end{array}$ \\
& In-house ELISA IgG & Doubtful $\geq 0.8$ to $<1.1$ \\
& Positive $\geq 1.1$
\end{tabular}


Table 1. Cont.

\begin{tabular}{ccc}
\hline Pathogen & Test & Cut Off Value \\
\hline & Baermann test and stool culture (HUG) & Positive $/$ Negative \\
Entomoeba histolytica & Stool PCR (HUG) & Positive $/$ Negative \\
Trypanosoma cruzi & Chagas STAT-PAK ${ }^{\circledR}$ & Positive $/$ Negative \\
& ELISA IgG (HUG) & Positive $>1$ \\
Echinococcus multilocularis & ELISA IgG (UniBern) & Positive $/$ Negative \\
& E. multilocularis Em2 & Positive $\geq 80$ \\
Leishmania spp. & E. multilocularis Em18 & Negative $<80$ \\
\hline
\end{tabular}

ELISA: enzyme-linked immunosorbent assay. SWISS TPH: Swiss Tropical and Public Health Institute. HUG: Hôpitaux Universitaires de Genève. PCR: Polymerase Chain Reaction. UniBern: University Hospital of Bern. IFAT: immunofluorescent antibody test.

\subsection{Data Collection}

All data were collected between July 2020 and May 2021, from electronic records of the SMTH consultations, and were managed using REDCap ${ }^{\circledR}$ electronic data capture tools hosted at HUG. Sociodemographic and clinical variables were defined: sex, age, nationality, country of origin, disease for which the immunosuppression was prescribed and a history of travel to geographical regions endemic for the parasites for which screening was proposed: Asia, Africa, Latin America, the Mediterranean basin and the Middle East. The variable travel was treated as a categorical variable: (1) no travel or risk-prone travel less than 4 consecutive weeks, and (2) travel or having lived more than 4 consecutive weeks (including those who were born in endemic countries).

\subsection{Statistical Analysis}

To calculate the required sample size, a small exploratory analysis was performed on a sample of 100 patients who had attended the SMTH consultation. In this sample the prevalence of LTBI was estimated at $8 \%$. Based on this finding, considering an alpha error of $2.5 \%$ we obtained a sample size needed of 457 patients. Statistical analysis was performed using StataCorp 2019 (Stata Statistical Software: Release 16, StataCorp LLC, College Station, TX, USA). Descriptive analyses were performed to describe the baseline demographic and clinical characteristics of the study population. Prevalence of LPI or LTBI was estimated by dividing the total number of patients tested positive by the total number of patients screened. For the two most prevalent diseases, LTBI and strongyloidiasis, a bivariate analysis using $2 \times 2$ tables and chi-square test or Fisher exact were done to explore their association with sociodemographic and clinical characteristics like immunosuppression, travel exposure, country of origin, age and sex. Additionally, risk factors for LTBI and strongyloidiasis were analysed using Poisson regression model with robust variance to estimated prevalence ratios (PR) and their respective $95 \%$ confidence interval $(95 \%$ CI). Only unadjusted models were estimated for strongyloidiasis because of the small number of events, while the model with tuberculosis as an outcome was also adjusted by immunosuppression; that was considered a confounding factor because it reduces the sensitivity of the QFT [13] and can reduce a patient's travel.

\section{Results}

From a total of 570 patients that attended the immunosuppressed consultation at SMTH, 406 met the study inclusion criteria and were included for further analyses. Excluded patients were those who refused to participate in clinical research study, had no indication to perform a screening test due to lack of exposure or type of immunosuppression and those who refused to perform the tests. A total of 259 (63.7\%) patients were females and the median age was 42.2 (range 18-84) years old. Most patients were born in Switzerland, $20.7 \%$ were native of a Mediterranean country or the Middle East, while $5 \%, 4.7 \%$ and $3 \%$ of patients were native of Latin America, Africa and Asia, respectively. 
More than half of the patients were immunosuppressed at the time of the QFT (52\%) or serological screening (57.6\%). Table 2 summarizes the patient baseline demographic and clinical characteristics.

Table 2. Patient baseline characteristics.

\begin{tabular}{|c|c|}
\hline Characteristic & $N=406$ \\
\hline \multicolumn{2}{|l|}{ Sex, $n(\%)$} \\
\hline Female & $259(63.7 \%)$ \\
\hline Male & $147(36.3 \%)$ \\
\hline Age, median (range) & $42.2(18-84)$ \\
\hline \multicolumn{2}{|l|}{ Nationality, $n(\%)$} \\
\hline Switzerland/Europe & $347(85.5 \%)$ \\
\hline Others & $59(14.5 \%)$ \\
\hline \multicolumn{2}{|l|}{ Region of origin, $n(\%)$} \\
\hline Africa & $19(4.7 \%)$ \\
\hline Asia & $12(3.0 \%)$ \\
\hline Mediterranean Basin and Middle East & $84(20.7 \%)$ \\
\hline Latin America & $20(5.0 \%)$ \\
\hline Northern Europe, USA, Australia & $271(66.7 \%)$ \\
\hline \multicolumn{2}{|l|}{ Travel, $n(\%)$} \\
\hline \multicolumn{2}{|l|}{ Africa } \\
\hline for more than 4 consecutive weeks * & $30(7.4 \%)$ \\
\hline less than 4 consecutive weeks or never & $317(78.0 \%)$ \\
\hline unknown duration & $59(14.6 \%)$ \\
\hline \multicolumn{2}{|l|}{ Asia } \\
\hline for more than 4 consecutive weeks * & $41(10.0 \%)$ \\
\hline less than 4 weeks or never & $284(70.0 \%)$ \\
\hline unknown duration & $81(20.0 \%)$ \\
\hline \multicolumn{2}{|l|}{ Mediterranean Basin and Middle East } \\
\hline for more than 4 consecutive weeks * & $111(27.4 \%)$ \\
\hline less than 4 weeks or never & $158(38.9 \%)$ \\
\hline unknown duration & $137(33.7 \%)$ \\
\hline \multicolumn{2}{|l|}{ Latin America } \\
\hline for more than 4 consecutive weeks * & $37(9.1 \%)$ \\
\hline less than 4 consecutive weeks or never & $310(76.3 \%)$ \\
\hline unknown duration & $59(14.5 \%)$ \\
\hline \multicolumn{2}{|l|}{ Disease for which ISIM drugs were prescribed } \\
\hline Multiple sclerosis & $282(69.4 \%)$ \\
\hline Rheumatic disease & $35(8.5 \%)$ \\
\hline Dermatological disease & $14(3.4 \%)$ \\
\hline Inflammatory bowel disease & $7(1.7 \%)$ \\
\hline Organ transplantation & $17(4.2 \%)$ \\
\hline Other: including pre transplantation screening & $54(13.3 \%)$ \\
\hline Immunosuppression at the time of the Quantiferon test, $n(\%)$ & $184(52 \%) \diamond$ \\
\hline Immunosuppression at the time of the serological screening, $n(\%)$ & $220(57.6 \%)$ \\
\hline
\end{tabular}

USA: United States of America. ISIM: immunosuppressive and immunomodulatory (ISIM) agents. * Including country of origin. $\diamond^{\diamond} n=353 .{ }^{\bullet} n=382$.

\subsection{Prevalence of Parasitic and Latent Tuberculosis Infection}

The most frequently performed diagnostic test was Strongyloides stercoralis serology (368/406, 90.6\%), followed by QFT (353/406, 86.9\%) and Leishmaniasis spp. serology $(299 / 406,73.6 \%)$ (Table 3). The QFT test was positive in $6.7 \%(24 / 353)$ of the patients tested. The seroprevalence of strongyloidiasis was $2.2 \%$ (8/368). The improved faecal technique stool test for the direct detection of Strongyloides stercoralis larvae performed in 38 patients remained negative in all cases. Latent amoebiasis $(1 / 32,3.1 \%)$ and leishmaniasis $(1 / 299,0.3 \%)$ were diagnosed in one patient each. No cases of Trypanosoma cruzi $(0 / 64)$ or Echinococcus multilocularis infection were detected (0/56). During the time frame of the study no patients developed active Tuberculosis or Strongyloides hyperinfection. 
Table 3. Results of screening tests for latent tuberculosis and parasitic infections.

\begin{tabular}{lccc}
\hline \multicolumn{1}{c}{ Pathogen } & Number of Test Done & Positive $\boldsymbol{n}$ (\%) & 95\% CI \\
\hline $\begin{array}{l}\text { Mycobacterium tuberculosis } \\
\text { Strongyloides spp. }\end{array}$ & 353 & $24(6.7 \%)$ & $4.6-10.0$ \\
- Strongyloides spp. in-house & & & \\
ELISA IgG & 368 & $6(1.6 \%)$ & $0.7-3.6$ \\
- Strongyloides spp. ELISA IgG & & $5(83.3 \%)$ & $2.3-9.8$ \\
$\begin{array}{l}\text { Euroimmune }{ }^{\circledR} \text { (Confirmation test) } \\
\text { - Baermann test and stool culture }\end{array}$ & 6 & 0 & - \\
- a Definition of positive: in-house & 38 & $8(2.2 \%)$ & $0.9-4.2$ \\
$>0.7$ or Euroimmune ${ }^{\circledR}$ positive & 368 & $1(3.1 \%)$ & $0.1-16$ \\
Entamoeba histolytica & 32 & 0 & - \\
Trypanosoma cruzi & 64 & 0 & - \\
Echinococcus multilocularis & 56 & $1(0.3 \%)$ & $<0.1-2.3$ \\
Leishmania spp. & 299 &
\end{tabular}

a Definition of a positive result has changed 1 September 2018 because a confirmatory test was introduced; patients were considered as positive according to the definition of positive result at the time of the execution of the test. ELISA: enzyme-linked immunosorbent assay.

\subsection{Risk Factor for LTBI and Strongyloidiasis}

Having travelled $>4$ consecutive weeks or having an origin from a high-prevalence country was a risk factor for LTBI after adjustment for immunosuppression (PR $=3.4,95 \%$ CI: 1.4-8.2 and 4.0, 95\% CI: 1.8-9.9, respectively). For strongyloidiasis, the prevalence of this condition in those with an immunosuppressed status was $90 \%$ less in comparison with those not immunosuppressed ( $\mathrm{PR}=0.1,95 \% \mathrm{CI}: 0.01-0.8$ ). Travel exposure and originating from an endemic country was not statistically associated with positive screening test (PR $=1.7,95 \%$ CI: 0.4-7.0, and 3.2, 95\% CI: 0.8-13.4, respectively) (Table 4).

Table 4. Risk factors for latent tuberculosis infection (LTBI) and Strongyloidiasis.

\begin{tabular}{|c|c|c|c|c|}
\hline Characteristic & Positive & Negative * & $\begin{array}{l}\text { Crude PR } \\
(95 \% \text { CI })\end{array}$ & $\begin{array}{l}\text { Adjusted PR * } \\
\text { (95\% CI) }\end{array}$ \\
\hline \multicolumn{5}{|l|}{ LTBI } \\
\hline \multicolumn{5}{|c|}{ Originate from high prevalence regions } \\
\hline No & $8(3.3 \%)$ & 231 & Ref & Ref \\
\hline Yes & $16(14.0 \%)$ & 98 & $4.2(1.8-9.5)$ & $4.0(1.8-8.9)$ \\
\hline \multicolumn{5}{|l|}{ Travel } \\
\hline No & $6(3.1 \%)$ & 184 & Ref & Ref \\
\hline Yes & $18(11.0 \%)$ & 145 & $3.5(1.4-8.6)$ & $3.4(1.4-8.2)$ \\
\hline \multicolumn{5}{|c|}{ Immunosuppression } \\
\hline No & $15(8.9 \%)$ & 154 & Ref & Ref \\
\hline Yes & $9(4.9 \%)$ & 175 & $0.5(0.2-1.2)$ & \\
\hline Age & - & - & $1.0(0.9-1.0)$ & $1.0(0.9-1)$ \\
\hline \multicolumn{5}{|l|}{ Sex } \\
\hline Female & $17(7.5 \%)$ & 208 & Ref & Ref \\
\hline Male & $7(5.5 \%)$ & 121 & $0.7(0.3-1.7)$ & $0.7(0.3-1.6)$ \\
\hline \multicolumn{5}{|l|}{ Strongyloidiasis } \\
\hline \multicolumn{5}{|c|}{ Originate from endemic country } \\
\hline No & $3(1.2 \%)$ & 240 & Ref & - \\
\hline Yes & $5(4.0 \%)$ & 120 & $3.2(0.8-13.4)$ & - \\
\hline
\end{tabular}


Table 4. Cont.

\begin{tabular}{|c|c|c|c|c|}
\hline Characteristic & Positive & Negative $*$ & $\begin{array}{l}\text { Crude PR } \\
(95 \% \text { CI })\end{array}$ & $\begin{array}{l}\text { Adjusted PR * } \\
\qquad(95 \% \mathrm{CI})\end{array}$ \\
\hline Travel & & & & - \\
\hline No & $3(1.6 \%)$ & 183 & Ref & - \\
\hline Yes & $5(2.7 \%)$ & 177 & $1.7(0.4-7.0)$ & \\
\hline \multicolumn{5}{|c|}{ Immunosuppression } \\
\hline No & $7(3.2 \%)$ & 211 & Ref & - \\
\hline Yes & $1(0.6 \%)$ & 149 & $0.1(0.01-0.8)$ & - \\
\hline Age & - & - & $1.0(0.9-1.0)$ & - \\
\hline \multicolumn{5}{|l|}{ Sex } \\
\hline Female & $3(1.3 \%)$ & 226 & Ref & \\
\hline Male & $5(3.6 \%)$ & 132 & $2.8(0.7-11.5)$ & - \\
\hline
\end{tabular}

PR: odd ratio; CI: confidence interval. * Adjusted by immunosuppression status for tuberculosis. * For TB indeterminate results considered as negative.

\section{Discussion}

To our knowledge this study is one of the first to evaluate the results of a systematically performed combined LTBI and parasitic screening in immunosuppressed patients. We report a prevalence of $6.7 \%$ (95\% CI $4.6-10)$ for LTBI and $2.2 \%$ (95\% CI: $0.9-4.2)$ for strongyloidiasis in 406 patients with various chronic conditions and ongoing or impending ISIM drug treatment.

Different studies have shown a LTBI prevalence ranging from 3\% to $13 \%$ in highincome countries, from $10 \%$ to $20 \%$ in southern and eastern Mediterranean and Latin America and, from $20 \%$ to $30 \%$ in sub-Saharan Africa, Indian subcontinent, and southeast Asia [14,15]. The prevalence founded in the population studied is consistent to its mixed origins.

Having travelled $>4$ consecutive weeks or originating from a high-prevalence country increased the prevalence of LTBI in 3.4 and 4.0 times, respectively. The decision to screen for LTBI need to be guided by the type of ISIM treatment prescribed (Figure 1), but a detailed background history and risk-factor assessment (travel or originating from endemic areas) should be part of the anamnesis of the immunosuppressed patient [16].

Variable consensus guidelines recommend routine screening for LTBI before initiation of different types of ISIM $[7,17]$. In contrast, there are less data on the screening of imported parasitic disease in that context, resulting in lack of standard guidance [18]. The strongyloidiasis seroprevalence found in our study is consistent with what was previously found among renal allograft recipients in Austria (3\%), another non-endemic European country [19]. Travel exposure and origin from an endemic country was not associated with a positive screening test, probably due to insufficient power of the study. Considering the lethal risk of hyperinfection syndrome in case of immunosuppression and the availability of a safe treatment simple to administer (oral ivermectin), screening for strongyloidiasis before or during immunosuppression for patients with current or past exposure in an endemic region appears to be justified and should be implemented, even in low-prevalence settings.

It is known that immunosuppression reduces the sensitivity of Strongyloides stercoralis serological tests [20], and this likely explains why we found a lower seroprevalence in immunosuppressed than in non-immunosuppressed patients $(\mathrm{PR}=0.1)$. There is therefore the paradox that people with a higher risk of developing a more severe infection are more difficult to diagnose. For this reason, it is advisable to test patients prior to initiation of immunosuppressive treatments, if feasible. Furthermore, the gold standard for the diagnosis of latent strongyloidiasis should include both a serological test and an improved faecal technique stool test. If this dual screening cannot be implemented, a preventive 
treatment is recommended for patients coming from highly endemic regions before starting a chronic immunosuppressive treatment, i.e., ivermectin $200 \mathrm{mcg} / \mathrm{kg}$ once a day for two days $[10,21]$. This same recommendation is currently being reiterated for patients infected with SARS-CoV-2 coming from high endemic regions who are undergoing corticosteroid therapy [22].

A single case with positive serology for leishmaniasis was detected. Viscerotropic leishmaniasis can reactivate during immunosuppressive treatment, as has been shown for solid-organ transplant recipients and other states of immunosuppression [23]. The prevalence of leishmaniasis is low in Europe (0.02-0.49/100,000, but higher in southern Europe) [24]; therefore, screening for this parasite, at least in central and northern Europeans, seems not justified. Considering the findings of our study, we have changed our screening practices accordingly at the SMTH.

The single case of amoebiasis was a female of Indian origin who had just returned from her home country, and the decision to perform the stool screening test according to existing criteria was justified (Figure 1). No case of Trypanosoma cruzi infection (Chagas disease) was detected at our consultation. However, during the time period of the study, two patients from Bolivia with positive Trypanosoma cruzi serology were identified before starting their immunosuppressive therapy and were referred to the SMTH consultation. They were not included since the tests had been performed outside our institution. With Geneva being particularly cosmopolitan and having a strong immigration from Bolivia, Chagas disease is well known by the local medical community [25]. As a result, many such immigrants are screened at their first contact with the healthcare system at our institution, perhaps more consistently as compared to centres where the disease is less known. It is very important to raise awareness for Chagas disease, given its high prevalence in Latin America and the increasing movements of populations from this continent around the globe, as the disease can reactivate during immunosuppression with fatal outcomes if not treated [26]. No case of Echinococcus multilocularis, an endemic but rare infection in Switzerland (annual incidence 0.15/100,000 [27]) was detected in our study. However, as immunosuppression can increase the incidence and the morbidity of the disease, [28] screening immunosuppressed patient with clear risk factors [12] seems justified. Serology sensitivity is normally above $90 \%$ [29] but can be reduced by immunosuppression [28]. Abdominal ultrasound (US) is too expensive and time consuming to be used as a screening test considering the low prevalence of the disease. In our centre we will continue to use serological screening in case of clear exposition and reserve the US in a "case-bycase" management for immunosuppressed patients and for symptomatic patients with non-specific gastrointestinal symptoms or elevation in liver enzyme.

The main limitation of our study was the fact that it was single centre with a relatively small sample size, which restrained the detection of rare infections (e.g., Enterococcus multilocularis, Leishmania spp.) and the identification of risk factors for most latent infections. Expanded multicentric studies should be performed to assess the prevalence of these imported parasitic infections and their risk factors in low-prevalence countries, and to design evidence-based and cost-effective strategies for their detection and management. Another possible bias was that in Switzerland, undocumented migrants may have less access to specialized medical services because purchasing private health insurance is mandatory to access the healthcare system and sometime franchises need to be paid out of pocket. The Swiss canton of Geneva has implemented primary care services within the public healthcare system for undocumented migrants that cannot purchase insurance, but probably they still receive less care than the general population due to administrative barriers and fear of denunciation [5]. This could explain the fact that a smaller proportion of our patients were born outside Europe in comparison to the Geneva general population, in association with the fact that the majority of patients were affected by multiple sclerosis, which is more prevalent in Caucasian patients [30].

The changes in diagnostic procedures for strongyloidiasis could have introduced a bias because patients with a doubtful screening test are now undergoing a confirmation 
test, while before September 2018 they were considered as negative. Immunosuppression is known for reducing the sensitivity of strongyloidiasis serology [20] while it does not affect the result of the Baermann or culture stool tests, and for this reason a dual test (serology and stool) is recommended [11].

In the study population, the implementation of the stool test was irregular, deviating from the algorithm described in Figure 1 due to practical (the need of a second consultation, the requirement that the stool sample be analysed within a $4 \mathrm{~h}$ delay) and economic reasons, so the Strongyloides prevalence could have been underestimated. On the contrary, even if it represents a worldwide trend, Geneva is a region with a high proportion of immigrants, and the prevalence of the diseases that we found are unlikely to be typical of regions with less international admixture.

\section{Conclusions}

Screening before immunosuppressive therapy needs to be individualized depending on the patient's exposure to pathogens: strongyloidiasis, amoebiasis and Chagas disease need to be excluded if the patient is native or has travelled for several consecutive weeks to a high-prevalence region. LTBI needs to be ruled out according to ISIM agents and for risk-factor assessment. For strongyloidiasis, in immunosuppressed patients a combined screening approach (serology and stool testing) is indicated. As E. multilocularis is endemic in Switzerland, screening patients with specific exposure is probably justified. All these parasitic infections belong to the group of neglected tropical diseases (NTDs), and it is not surprising that they have been so little studied, also in this particular context. Calling for more studies to improve detection and management of these conditions is part of the fight against this neglect.

Supplementary Materials: The following are available online at https: / www.mdpi.com/article / 10.3390/tropicalmed6030170/s1, Table S1: list of immunomodulatory or immunosuppressive treatments in alphabetic order.

Author Contributions: Conceptualization, L.C., and G.E.; methodology, L.C., G.E., M.L.-P., Software L.C.; validation, L.C. and M.L.-P.; formal analysis, L.C. and M.L.-P.; investigation, L.C.; data curation, L.C.; writing-original draft preparation, L.C. and J.-M.S.; writing-review and editing, G.E.; supervision, F.C. and D.N. All authors have read and agreed to the published version of the manuscript.

Funding: This work was supported by the Division of Humanitarian and Tropical Medicine of the HUG.

Institutional Review Board Statement: The study was conducted according to the guidelines of the Declaration of Helsinki, and approved by the Ethics Committee of Geneva (Commission cantonale d'éthique de la recherche), approval No. 2020-01647, 21 July 2020.

Informed Consent Statement: Patient consent was waived due to retrospective non interventional nature of the study, exposing patients to no risk or harm. Exception was made for patients whose medical charts contain documentation of their express refusal to participate in a clinical study, they were not included in the study.

Data Availability Statement: The data presented in this study are available on request from the corresponding author. The data are not publicly available due to privacy reason.

Acknowledgments: We thank Rob Hooft van Huijsduijnen for editorial assistance and Michel Boulvain for the supervision of the protocol redaction.

Conflicts of Interest: The authors have no conflict of interest to declare.

\section{References}

1. Wallace, B.I.; Kenney, B.; Malani, P.N.; Clauw, D.J.; Nallamothu, B.K.; Waljee, A.K. Prevalence of Immunosuppressive Drug Use Among Commercially Insured US Adults, 2018-2019. JAMA Netw. Open 2021, 4, e214920. [CrossRef] 
2. Patel, M.; Chen, J.; Kim, S.; Garg, S.; Flannery, B.; Haddadin, Z.; Rankin, D.; Halasa, N.; Talbot, H.K.; Reed, C. Analysis of MarketScan Data for Immunosuppressive Conditions and Hospitalizations for Acute Respiratory Illness, United States. Emerg. Infect. Dis. 2020, 26, 1720-1730. [CrossRef] [PubMed]

3. Sánchez-Montalvá, A.; Camps, I.R.; Barba, P.; Valcarcel, D.; Sulleiro, E.; Sanz-García, E.; Molina, I.; Salvador, F. Imported Disease Screening Prior to Chemotherapy and Bone Marrow Transplantation for Oncohematological Malignancies. Am. J. Trop. Med. Hyg. 2016, 95, 1463-1468. [CrossRef]

4. Statistiques Cantonal Etat de Geneve. Available online: https://www.ge.ch/statistique/domaines/apercu.asp (accessed on 27 July 2021).

5. Jackson, Y.; Paignon, A.; Wolff, H.; Delicado, N. Health of undocumented migrants in primary care in Switzerland. PLoS ONE 2018, 13, e0201313. [CrossRef] [PubMed]

6. Longchamp, C.; Aebersold, M.; Rousselot, B.; Ratelband-Pally, S. Sans Papier in der Schweiz: Arbeitsmarkt, nicht Asylpolitik ist entscheidend; Gfs: Bern, Switzerland, 2005.

7. Davis, J.S.; Ferreira, D.; Paige, E.; Gedye, C.; Boyle, M. Infectious Complications of Biological and Small Molecule Targeted Immunomodulatory Therapies. Clin. Microbiol. Rev. 2020, 33. [CrossRef] [PubMed]

8. Goyal, A.; Goyal, K.; Merola, J.F. Screening and Vaccinations in Patients Requiring Systemic Immunosuppression: An Update for Dermatologists. Am. J. Clin. Dermatol. 2015, 16, 179-195. [CrossRef] [PubMed]

9. Levi, M.E.; Kumar, D.; Green, M.; Ison, M.G.; Kaul, D.; Michaels, M.G. Considerations for Screening Live Kidney Donors for Endemic Infections: A Viewpoint on the UNOS Policy: Live Kidney Donor Screening for Endemic Infections. Am. J. Transplant. 2014, 14, 1003-1011. [CrossRef]

10. Requena-Méndez, A.; Muñoz, J.; Gomez-Junyent, J.; Bisoffi, Z.; Buonfrate, D.; Zammarchi, L. Evidence-Based Guidelines for Screening and Management of Strongyloidiasis in Non-Endemic Countries. Am. J. Trop. Med. Hyg. 2017, 97, 645-652. [CrossRef]

11. Eperon, G.; Bühler, S.; Enriquez, N.; Vaudaux, B. The immunosuppressed traveler: Vaccination guidelines. Rev. Med. Suisse 2018, 14, 922-933. [PubMed]

12. Kern, P.; Ammon, A.; Kron, M.; Sinn, G.; Sander, S.; Petersen, L.R.; Gaus, W.; Kern, P. Risk factors for alveolar echinococcosis in humans. Emerg. Infect. Dis. 2004, 10, 2088-2093. [CrossRef] [PubMed]

13. Ramos, J.M.; Masiá, M.; Rodriguez, J.C.; Lopez, C.; Padilla, S.; Robledano, C.; Navarro-Blasco, F.J.; Matarredona, J.; GarciaSepulcre, M.F.; Gutiérrez, F. Negative effect of immunosuppressive therapy in the performance of the QuantiFERON Gold In-Tube test in patients with immune-mediated inflammatory diseases. Clin. Exp. Med. 2012, 13, 177-186. [CrossRef]

14. Cohen, A.; Mathiasen, V.D.; Schön, T.; Wejse, C. The global prevalence of latent tuberculosis: A systematic review and metaanalysis. Eur. Respir. J. 2019, 54, 1900655. [CrossRef] [PubMed]

15. Houben, R.M.G.J.; Dodd, P.J. The Global Burden of Latent Tuberculosis Infection: A Re-estimation Using Mathematical Modelling. PLoS Med. 2016, 13, e1002152. [CrossRef] [PubMed]

16. Hasan, T.; Au, E.; Chen, S.; Tong, A.; Wong, G. Screening and prevention for latent tuberculosis in immunosuppressed patients at risk for tuberculosis: A systematic review of clinical practice guidelines. BMJ Open 2018, 8, e022445. [CrossRef] [PubMed]

17. Chadwick, D.R.; Sayeed, L.; Rose, M.; Budd, E.; Mohammed, M.; Harrison, S.; Azad, J.; Maddox, J. Adherence to guidelines across different specialties to prevent infections in patients undergoing immunosuppressive therapies. BMC Infect. Dis. 2020, 20, 359. [CrossRef]

18. Sullivan, R.; Gaskell, C.; Lewis, C.R.; Vollmer-Conna, U.; Post, J.J. Infectious disease screening in patients prior to undergoing immunosuppressive therapy. Int. J. Clin. Pract. 2019, 73, e13406. [CrossRef]

19. Winnicki, W.; Eder, M.; Mazal, P.; Mayer, F.J.; Sengölge, G.; Wagner, L. Prevalence of Strongyloides stercoralis infection and hyperinfection syndrome among renal allograft recipients in Central Europe. Sci. Rep. 2018, 8, 15406. [CrossRef]

20. Luvira, V.; Chantawat, N.; Naaglor, T.; Dekumyoy, P.; Mungthin, M.; Trakulhun, K.; Phiboonbanakit, D.; Pakdee, W. Comparative Diagnosis of Strongyloidiasis in Immunocompromised Patients. Am. J. Trop. Med. Hyg. 2016, 95, 401-404. [CrossRef]

21. Presumptive Treatment and Screening for Strongyloidiasis, Infections Caused by Other Soil-Transmitted Helminths, and Schistosomiasis Among Newly Arrived Refugees. [Internet]. CDC Website; 2021. Available online: https://www.cdc.gov/ immigrantrefugeehealth/guidelines/domestic/intestinal-parasites-domestic.html (accessed on 3 July 2021).

22. Stauffer, W.M.; Alpern, J.D.; Walker, P.F. COVID-19 and Dexamethasone: A Potential Strategy to Avoid Steroid-Related Strogyloides Hyperinfection. JAMA 2020, 324, 623. [CrossRef]

23. Akuffo, H.; Costa, C.; Van Griensven, J.; Burza, S.; Moreno, J.; Herrero, M. New insights into leishmaniasis in the immunosuppressed. PLoS Negl. Trop. Dis. 2018, 12, e0006375. [CrossRef]

24. Dujardin, J.-C.; Campino, L.; Cañavate, C.; Dedet, J.-P.; Gradoni, L.; Soteriadou, K.; Mazeris, A.; Özbel, Y.; Boelaert, M. Spread of Vector-borne Diseases and Neglect of Leishmaniasis, Europe. Emerg. Infect. Dis. 2008, 14, 1013-1018. [CrossRef] [PubMed]

25. Jackson, Y.; Chappuis, F. Chagas disease in Switzerland: History and challenges. Eurosurveillance 2011, 16, 19963. [CrossRef]

26. Moreira, M.d.C.V.; Cunha-Melo, R.J. Chagas Disease Infection Reactivation after Heart Transplant. Trop. Med. 2020, 5, 106. [CrossRef]

27. Schweiger, A.; Ammann, R.W.; Candinas, D.; Clavien, P.-A.; Eckert, J.; Gottstein, B.; Halkic, N.; Muellhaupt, B.; Prinz, B.M.; Reichen, J.; et al. Human Alveolar Echinococcosis after Fox Population Increase, Switzerland. Emerg. Infect. Dis. 2007, 13, 878-882. [CrossRef] [PubMed] 
28. Chauchet, A.; Grenouillet, F.; Knapp, J.; Richou, C.; Delabrousse, E.; Dentan, C.; Millon, L.; Di Martino, V.; Contreras, R.; Deconinck, E.; et al. Increased Incidence and Characteristics of Alveolar Echinococcosis in Patients With Immunosuppression-Associated Conditions. Clin. Infect. Dis. 2014, 59, 1095-1104. [CrossRef] [PubMed]

29. Knapp, J.; Sako, Y.; Grenouillet, F.; Bresson-Hadni, S.; Richou, C.; Gbaguidi-Haore, H.; Ito, A.; Millon, L. Comparison of the serological tests ICT and ELISA for the diagnosis of alveolar echinococcosis in France. Parasite 2014, 21, 34. [CrossRef] [PubMed]

30. Leray, E.; Moreau, T.; Fromont, A.; Edan, G. Epidemiology of multiple sclerosis. Rev. Neurol. Paris 2016, 172, 3-13. [CrossRef] [PubMed] 